\title{
Comparative Gamma Spectroscopy with Srl2(Eu), GYGAG(Ce) and Bi-loaded Plastic Scintillators
}

N. J. Cherepy

November 22, 2010

IEEE Nuclear Science Symposium

Knoxville, TN, United States

October 30, 2010 through November 6, 2010 
This document was prepared as an account of work sponsored by an agency of the United States government. Neither the United States government nor Lawrence Livermore National Security, LLC, nor any of their employees makes any warranty, expressed or implied, or assumes any legal liability or responsibility for the accuracy, completeness, or usefulness of any information, apparatus, product, or process disclosed, or represents that its use would not infringe privately owned rights. Reference herein to any specific commercial product, process, or service by trade name, trademark, manufacturer, or otherwise does not necessarily constitute or imply its endorsement, recommendation, or favoring by the United States government or Lawrence Livermore National Security, LLC. The views and opinions of authors expressed herein do not necessarily state or reflect those of the United States government or Lawrence Livermore National Security, LLC, and shall not be used for advertising or product endorsement purposes. 


\title{
Comparative Gamma Spectroscopy with $\operatorname{SrI}_{2}(\mathrm{Eu})$, GYGAG(Ce) and Bi-loaded Plastic Scintillators
}

\author{
N.J. Cherepy, Member, IEEE, S.A. Payne, Member, IEEE, B.W. Sturm, Member, IEEE, J.D. Kuntz, \\ Z.M. Seeley, B.L. Rupert, R.D. Sanner, O.B. Drury, T.A. Hurst, S.E. Fisher \\ M. Groza, L. Matei, A. Burger, Member, IEEE, \\ R. Hawrami, Member, IEEE, K.S. Shah, Member, IEEE, and L.A. Boatner Member, IEEE
}

\begin{abstract}
We are developing new scintillator materials that offer potential for high resolution gamma ray spectroscopy at low cost. Single crystal $\operatorname{SrI}_{2}(\mathrm{Eu})$ offers $\sim 3 \%$ resolution at $662 \mathrm{keV}$, in sizes of $\sim 1 \mathrm{in}^{3}$. We have developed ceramics processing technology allowing us to achieve cubic inch scale transparent ceramic scintillators offering gamma spectroscopy performance superior to NaI(Tl). We fabricated a bismuth-loaded plastic scintillator that demonstrates energy resolution of $\sim 8 \%$ at $662 \mathrm{keV}$ in small sizes.
\end{abstract}

Index Terms - Scintillators, strontium iodide, ceramic scintillators, gamma ray spectrometers, transparent ceramics, plastic scintillators

\section{INTRODUCTION}

G amma ray spectroscopy can be used to identify the presence of weak radioactive sources within natural background. The ability to discriminate close-lying spectral lines is strongly dependent upon the energy resolution of the detector. In addition to excellent energy resolution, large volume detectors are needed to acquire sufficient events, for example, to identify a radioactive anomaly moving past a detector. We have employed a "directed search" methodology for identifying potential scintillator materials candidates [1], resulting in the discovery of Europium-doped Strontium Iodide, $\mathrm{SrI}_{2}(\mathrm{Eu})$ [2-4], Cerium-doped Gadolinium Garnet [5,6], GYGAG(Ce), and Bismuth-loaded Polymers. These scintillators possess very low self-radioactivity, offer energy resolution of 3-8\% at $662 \mathrm{keV}$, and have potential to be grown cost-effectively to sizes similar to the most widely deployed gamma spectroscopy scintillator, Thallium-doped Sodium Iodide, $\mathrm{NaI}(\mathrm{Tl})$.

Manuscript received November 21, 2010. This work was supported by the Domestic Nuclear Detection Office in the Department of Homeland Security and by the National Nuclear Security Administration, Office of Nonproliferation Research and Development (NA-22) of the U.S.DOE under Contract No. DE-AC03-76SF00098, and was performed under the auspices of the U.S. DOE by Lawrence Livermore National Laboratory under Contract DE-AC52-07NA27344.

N.J. Cherepy, S.A. Payne, B.W. Sturm, J.D. Kuntz, Z.M. Seeley, B.L. Rupert, R.D.Sanner, O.B. Drury, T.A. Hurst, S.E. Fisher are with Lawrence Livermore National Laboratory, Livermore, CA 94550 (phone: +1-925-4243492; e-mail: cherepy1@1lnl.gov).

K.S. Shah is with Radiation Monitoring Devices (RMD), Watertown, MA M. Groza, L. Matei, and A. Burger are with Fisk Univ., Nashville, TN

L.A. Boatner is with Oak Ridge National Laboratory, Oak Ridge, TN

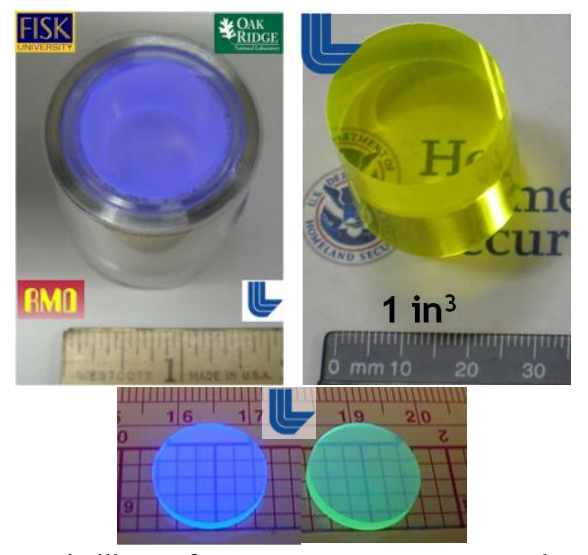

Fig. 1. New scintillators for gamma ray spectroscopy developed for DHS and DOE. (upper left) $\mathrm{SrI}_{2}(\mathrm{Eu})$ single crystal under UV excitation, (upper right) GYGAG(Ce) ceramic, (bottom) two Bi-loaded polymers under UV excitation.

In this study, gamma ray spectra of a variety of sources, were obtained employing $\operatorname{SrI}_{2}(\mathrm{Eu})$, GYGAG(Ce), Bi-loaded polymers, $\mathrm{LaBr}_{3}(\mathrm{Ce})$, and $\mathrm{NaI}(\mathrm{Tl})$. The effects of detector size, energy resolution, and background radioactivity (including self-radioactivity) on the ability to distinguish weak sources is quantified, based on a simple model, and qualitatively compared to laboratory data.

\section{SAMPLES}

\section{A. Strontium Iodide}

$\mathrm{SrI}_{2}(5 \mathrm{~mol} \% \mathrm{Eu})$ crystals are being grown at $\mathrm{RMD}$, Oak Ridge National Laboratory and Fisk University using the vertical Bridgman method. The crystals are grown in silica ampoules using anhydrous $\mathrm{SrI}_{2}$ beads (Aldrich, 99.99\%) and $\mathrm{EuI}_{2}$ powder (Aldrich, 99.9\%), as the starting materials [2-4]. Crystals from all three growers have offered similar performance. The crystal characterized in this report was grown at RMD, then packaged at LLNL. The crystal was cut into a tapered cylinder, polished and encapsulated in an aluminum can [7].

\section{B. Gadolinium Garnet Transparent Ceramics}

Transparent ceramic garnets were formed at LLNL using stoichiometric mixed metal oxide particles synthesized via flame spray pyrolysis (FSP), a nanoparticle production method developed by Pratsinis and co-workers [8] and Laine and co-workers [9]. Synthesis of FSP nanoparticles was carried out at LLNL, as well as by Nanocerox, Inc. The FSP nanoparticles are formed into a green body, vacuum sintered, 

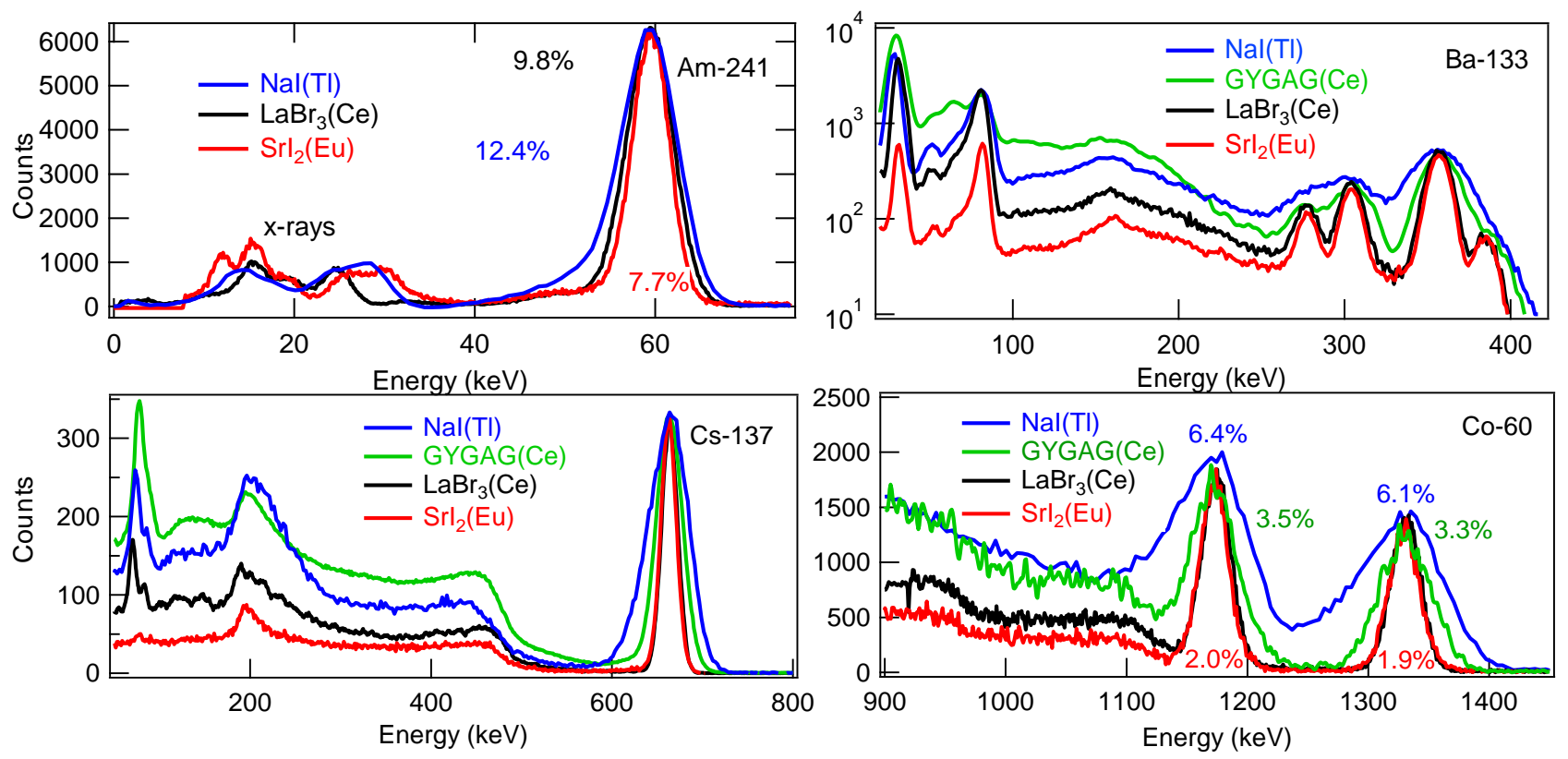

Fig. 2. Gamma spectra acquired with various sources using several scintillator materials. $\mathrm{NaI}(\mathrm{Tl})$ crystal is $\phi 2.54 \mathrm{~cm} \times 3.81 \mathrm{~cm}, \mathrm{LaBr} 3(\mathrm{Ce}) \mathrm{crystal}$ is $\phi 1.8$ $\mathrm{cm} \times 2 \mathrm{~cm}$, GYGAG(Ce) ceramic is $\phi 2.77 \mathrm{~cm} \times 0.62 \mathrm{~cm}$ and the $\mathrm{SrI}_{2}(\mathrm{Eu})$ crystal is an encapsulated tapered cylinder with $\phi 2.54 \mathrm{~cm} \times 2.7 \mathrm{~cm}$.

then hot-isostatic pressed into optically transparent parts [10]. The relative ease with which the GYGAG(Ce) ceramic is formed with high transparency is due to deliberate use of "intersubstitutional" cations, whereby the three different cation sites of the garnet unit cell are each occupied by more than one of the four cation species. This results in flexibility in stoichiometry, and ultimately, a high yield industrial manufacturing process due to excellent phase stability over a range of compositions.

\section{Bismuth-loaded Polymers}

Polymer scintillators with $40 \mathrm{wt} \%$ Bismuth were formed at LLNL by mixing a Bismuth metallo-organic with monomer and 3\% fluor, heating to melt, and subsequent polymerization of the homogeneous mixture. Two different fluors were investigated, an Iridium complex, emitting in the green, and diphenylanthracene, emitting in the blue.

\section{GAMMA SPECTROSCOPY}

Pulse height spectra were acquired with various radioactive sources, with scintillators coupled to a Hamamatsu R6231-100 PMT, a Tennelec TC243 amplifier (shaping times 8-12 microseconds), and recorded with an Amptek 8000A MCA. A comparison of the energy resolution obtained with the new scintillator materials and commercial $\mathrm{LaBr}_{3}(\mathrm{Ce})$ and $\mathrm{NaI}(\mathrm{Tl})$ crystals, using the Am-241, Ba-133, Cs-137 and Co-60 sources is shown in Figure 2.

To explore the ease of detection of a weak source with different scintillators, we measured a Cs-137 source at a 3 foot standoff with $\mathrm{NaI}(\mathrm{Tl}), \mathrm{LaBr}_{3}(\mathrm{Ce})$ and $\mathrm{SrI}_{2}(\mathrm{Eu})$, all $\sim 1 \mathrm{in}^{3}$ in size, with equivalent acquisition times. Figure 3 shows that the $662 \mathrm{keV}$ peak is readily observed in the $\mathrm{SrI}_{2}(\mathrm{Eu})$ spectrum, while the poorer energy resolution of $\mathrm{NaI}(\mathrm{Tl})$ degrades its ability to detect the source, and the intrinsic background in $\mathrm{LaBr}_{3}(\mathrm{Ce})(\mathrm{La}-138$ gammas at 789 and $1436 \mathrm{keV}$, betas in 0-
$255 \mathrm{keV}$ range, the Ba-138 32-37 keV x-rays, and sums of these) complicates its spectrum [11].

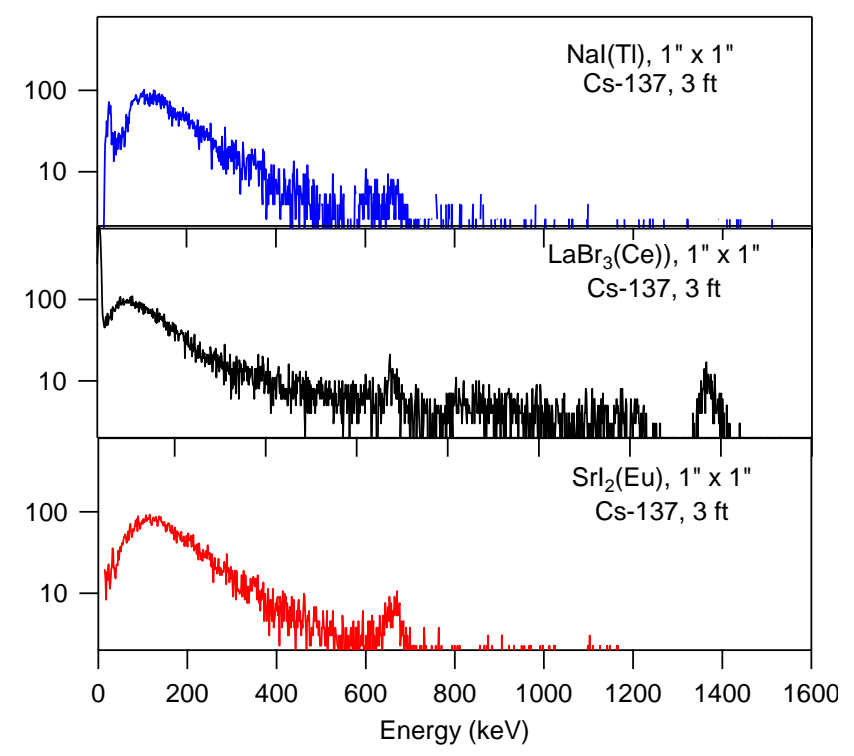

Fig. 3. Pulse height spectra of $\mathrm{NaI}(\mathrm{Tl}), \mathrm{LaBr}_{3}(\mathrm{Ce})$ and $\mathrm{SrI}_{2}(\mathrm{Eu})$, acquired under same conditions, for same scintillator size and acquisition time, using a low count-rate Cs-137 source.

Pulse height spectra were acquired with Am-241, Co-57 and Cs-137 sources of $1.5 \mathrm{~cm} \times 0.3 \mathrm{~cm}$ Bismuth-loaded polymer samples. Figure 4 shows that the energy resolution obtained for the sample containing the Iridium fluor is somewhat better than that of the diphenylanthracene activated polymer. This is likely due to the higher light yield with the Ir-complex, which collect both singlet and triplet excitons due to spin-orbit coupling [12]. Since the samples are so small and have only modest stopping power, escape peaks similar in intensity to the photopeak, are observed, from ${ }^{209} \mathrm{Bi} \mathrm{K}_{\alpha} \mathrm{X}$-rays at 74.8 and $77.1 \mathrm{keV}$. These initial results suggest that it may be possible 


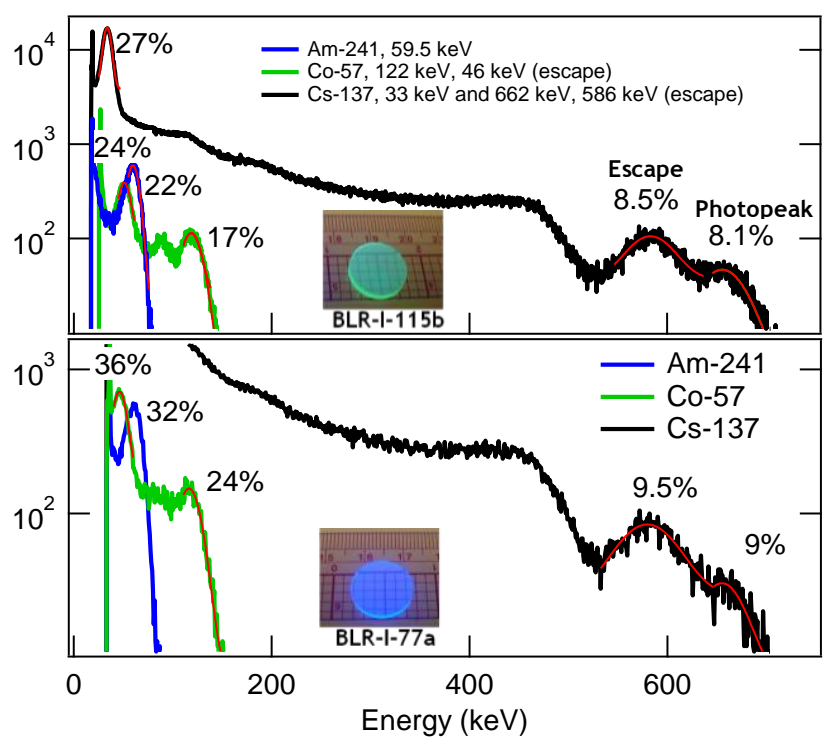

Fig. 4. Pulse height spectra of two $1.5 \mathrm{~cm} \times 0.3 \mathrm{~cm}$ Bismuth-loaded polymer samples, acquired with Am-241, Co-57 and Cs- 137 sources.

to produce polymer-based gamma spectrometers, with useful energy resolution for radioisotope identification, however larger samples must be fabricated and tested.

Figure 5 shows energy resolution obtained as a function of gamma ray energy for the scintillators described herein. The data may be fit to equation 1, comprised of the photon statistics term and a "B" factor that accounts for all nonidealities in the measurement, including intrinsic light yield non-proportionality, material response non-uniformity and light collection non-uniformity.

$$
\left.\mathrm{R}=\left\{\left[(\mathrm{A} / \mathrm{E})^{0.5}\right]^{2}+\mathrm{B}^{2}\right]\right\}^{0.5}
$$

In equation $1, \mathrm{~A}$ is a constant, $\mathrm{E}$ is the gamma energy, and $\mathrm{B}$ is required when there is deviation from pure photon statistics. For the data shown in Figure 5, the values for B obtained from the fits are shown in Table I. The large value of B for $\mathrm{NaI}(\mathrm{Tl})$ is thought to be due to its intrinsic non-proportionality. The much smaller value for $\operatorname{Srl}_{2}(\mathrm{Eu})$ likely results from light trapping, which may be addressed by careful optical design $[13,7]$. The origin of $\mathrm{B}$ value for $\mathrm{GYGAG}(\mathrm{Ce})$ is under investigation. Material response non-uniformity is likely the

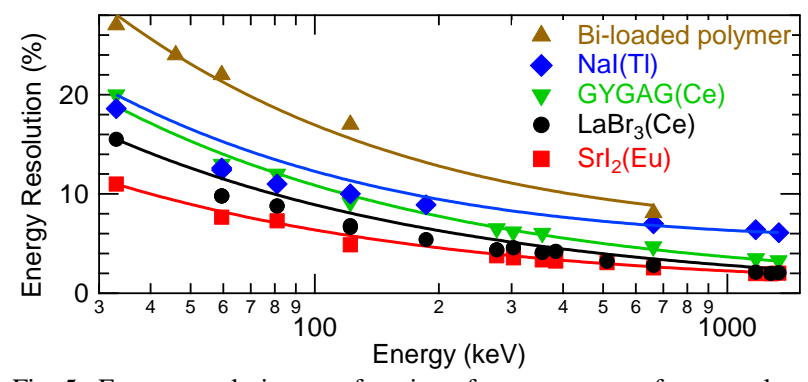

Fig. 5. Energy resolution as a function of gamma energy for several scintillators; data is fit to Eq. 1.

origin of the large $\mathrm{B}$ value for the Bi-loaded polymer scintillator, possibly due to its amorphous structure and phase segregation of $\mathrm{Bi}$ on the nanoscale, observable by electron microscopy.

From the analysis of Nelson, et al. [14], we have deduced that in the energy resolution range applicable to scintillators $(4-15 \%$ at $200 \mathrm{keV})$ a false alarm rate (FAR) for identification of spectral anomalies can be expressed:

$$
\mathrm{FAR} \sim \mathrm{R}^{3.4} /\left(\mathrm{S}_{\mathrm{PP}} / \mathrm{B}_{\mathrm{TOT}}\right)^{0.54}
$$

where $\mathrm{R}$ is the resolution of the instrument, $\mathrm{S}_{\mathrm{PP}}$ is the photopeak efficiency (product of the stopping power and the photofraction), and $\mathrm{B}_{\mathrm{TOT}}$ is the sum of the natural background $\left(\mathrm{B}_{\mathrm{NAT}}\right)$ and the self-radioactivity $\left(\mathrm{B}_{\mathrm{SELF}}\right)$ of the scintillator material. The self-radioactivity for $\operatorname{LaBr}_{3}(\mathrm{Ce})$ is approximately equivalent to the natural background rate. In terms of this performance metric, $\operatorname{SrI}_{2}(\mathrm{Eu})$ and $\mathrm{GYGAG}(\mathrm{Ce})$ appear promising. For resolution in the $200-\mathrm{keV}$ region, $\mathrm{SrI}_{2}(\mathrm{Eu})$ offers an overall reduction in false alarms of a factor of 3 compared to $\operatorname{LaBr}_{3}(\mathrm{Ce})$ and a factor of 14 better than $\mathrm{NaI}(\mathrm{Tl})$. These estimates may be qualitatively compared with the data shown in Fig. 3, where in low count spectra, the weak isolated gamma from Cs-137 is most readily identifiable with $\operatorname{SrI}_{2}(\mathrm{Eu})$. For GYGAG(Ce), the advantage is less pronounced, but offers more than $2 \mathrm{x}$ better performance than $\mathrm{NaI}(\mathrm{Tl})$ in the $200 \mathrm{keV}$ region, and in the $1200 \mathrm{keV}$ region, as seen in the Co-60 spectrum in Figure 2, the advantage of GYGAG(Ce) becomes more pronounced. The ease of manufacture and handling of transparent ceramic oxides, could result in an economic advantage for $\mathrm{GYGAG}(\mathrm{Ce})$ over $\mathrm{NaI}(\mathrm{Tl})$. Finally, the intrinsic energy resolution of both

TABLE II

\begin{tabular}{|c|c|c|c|c|c|c|c|c|}
\hline Scintillator & $\begin{array}{c}\text { Light Yield } \\
\text { (Photons/MeV) }\end{array}$ & $\begin{array}{c}\text { Energy } \\
\text { Resolution } \\
(662 \mathrm{keV})\end{array}$ & $\begin{array}{c}\text { NP Energy } \\
\text { Resolution }^{\mathrm{a}} \\
(662 \mathrm{keV})\end{array}$ & $\begin{array}{c}\text { B } \\
\text { (Eq. 1) }\end{array}$ & $\begin{array}{c}\text { Energy } \\
\text { Resolution } \\
(200 \mathrm{keV})\end{array}$ & $\begin{array}{l}\mathrm{S}_{\mathrm{PP}}, \% / \mathrm{cm} \\
(200 \mathrm{keV})\end{array}$ & $\begin{array}{c}\text { Radiation } \\
\text { Background }\end{array}$ & $\begin{array}{c}\text { Relative False } \\
\text { Alarm Rate, } \\
\phi 1.5 \times 1.5 \mathrm{~cm}\end{array}$ \\
\hline $\mathrm{NaI}(\mathrm{Tl})$ & 40,000 & $7 \%$ & $5.0 \%$ & 5.3 & $9 \%$ & 0.30 & $\mathrm{~B}_{\mathrm{NAT}}$ & 1 \\
\hline $\mathrm{SrI}_{2}(\mathrm{Eu})$ & 90,000 & $3 \%$ & $2.2 \%$ & 1.1 & $4.3 \%$ & 0.36 & $\mathrm{~B}_{\mathrm{NAT}}$ & 0.07 \\
\hline$(\mathrm{Gd}, \mathrm{Y})_{3}(\mathrm{Al}, \mathrm{Ga})_{5} \mathrm{O}_{12}(\mathrm{Ce})$ & 50,000 & $4.8 \%$ & $1.9 \%$ & 1.3 & $7.3 \%$ & 0.38 & $\mathrm{~B}_{\mathrm{NAT}}$ & 0.43 \\
\hline Standard PVT & 15,000 & $8 \%^{\mathrm{b}}$ & $3.6 \%$ & --- & $--^{c}$ & 0.0006 & $\mathrm{~B}_{\mathrm{NAT}}$ & $--{ }^{c}$ \\
\hline
\end{tabular}

COMPARISON OF PROPERTIES AND PERFORMANCE OF SEVERAL SCINTILlATORS FOR GAMMA RAY SPECTROSCOPY

${ }^{a}$ Non-proportionality-limited energy resolution determined by fits to data from the Scintillator Light Yield Non-Proportionality Characterization Instrument, see Reference 14.

${ }^{\mathrm{b}}$ Obtained from fitting the Compton Edge of the pulse height spectrum of Eljen EJ-200 plastic scintillator.

${ }^{\mathrm{c}}$ Not readily obtained due to extremely weak photopeak for this material.

${ }^{\mathrm{d}}$ False Alarm Rate (FAR) is described by Equation 2, for identifying a spectral anomaly in the vicinity of $200 \mathrm{keV}$. 
$\mathrm{SrI}_{2}(\mathrm{Eu})$ and $\mathrm{GYGAG}(\mathrm{Ce})$, as estimated from fitting data from the Scintillator Light Yield Non-Proportionality Characterization Instrument, is better than the current experimental values, shown in Table 1, and therefore we expect that with improved material quality and device design, their energy resolution may improve further $[15,16]$.

\section{SUMMARY}

We have identified several new scintillator materials through a "directed search" methodology. Among them, $\mathrm{SrI}_{2}(\mathrm{Eu})$ offers the highest energy resolution. Transparent ceramic GYGAG(Ce) offers high light yield, and gamma spectroscopy with better resolution than $\mathrm{NaI}(\mathrm{Tl})$. We have synthesized and characterized Bi-loaded polymer scintillators that can be used for gamma spectroscopy, and larger size samples are under development.

\section{REFERENCES}

[1] N.J. Cherepy, S.A. Payne, S.J. Asztalos, G. Hull, J.D. Kuntz, T. Niedermayr, S. Pimputkar, J.J. Roberts, R.D. Sanner, T.M. Tillotson, E. van Loef, C.M. Wilson, K.S. Shah, U.N. Roy, R. Hawrami, A. Burger, L.A. Boatner, W.-S. Choong, "Scintillators with Potential to Supersede Lanthanum Bromide," IEEE Trans. Nucl. Sci., vol. 56, 873-880 (2009).

[2] N.J. Cherepy, G. Hull, A. Drobshoff, S.A. Payne, E. van Loef, C. Wilson, K. Shah, U.N. Roy, A. Burger, L.A. Boatner, W-S Choong, W.W. Moses "Strontium and Barium Iodide High Light Yield Scintillators," Appl. Phys. Lett. 92, 083508 (2008).

[3] N. J. Cherepy, B. W. Sturm, O. B. Drury; T. A. Hurst. S. A. Sheets, L. E. Ahle, C. K. Saw, M. A. Pearson, S. A. Payne, A. Burger, L. A. Boatner, J. O. Ramey, E. V. van Loef, J. Glodo, R. Hawrami, W. M. Higgins, K. S. Shah, W. W. Moses, "SrI 2 scintillator for gamma ray spectroscopy," Proc. SPIE, 7449, 7449-0 (2009).

[4] N.J. Cherepy, S.A. Payne, R. Hawrami, A. Burger, L.A. Boatner, E. van Loef, K.S. Shah "Prospects for High Energy Resolution Gamma Ray Spectroscopy with Europium-Doped Strontium Iodide," Mater. Res. Soc. Symp. Proc. Vol. 1164, 1164-L11-04 (2009).

[5] N.J. Cherepy, J.D. Kuntz, J.J Roberts, T.A. Hurst, O.B. Drury, R.D. Sanner, T.M. Tillotson, S.A. Payne, "Transparent Ceramic Scintillator Fabrication, Properties and Applications," Proc. SPIE., 7079, 70790x 2008.

[6] N. J. Cherepy, J. D. Kuntz, Z. M. Seeley, S. E. Fisher, O. B. Drury, B. W. Sturm, T. A. Hurst, R. D. Sanner, J. J. Roberts, and S. A. Payne, "Transparent ceramic scintillators for gamma spectroscopy and radiography," Proc. SPIE, 7805, 78050I, 2010.

[7] B.W. Sturm, N.J. Cherepy, O.B. Drury, P.A. Thelin, S.E. Fisher, S.A. Payne, A. Burger, L.A. Boatner, J.O. Ramey, K.S. Shah, R. Hawrami , "Effects of Packaging $\operatorname{SrI}_{2}(\mathrm{Eu})$ Scintillator Crystals ," Nucl. Instr. Meth. $A$, in press, 2010.

[8] L. Mädler, H.K. Kammler, R. Mueller, S.E. Pratsinis, "Controlled synthesis of nanostructured particles by flame spray pyrolysis," Aerosol Sci. 33, 369, 2002.

[9] C.R. Bickmore, K.F. Waldner, D.R. Treadwell, R.M. Laine, "Ultrafine Spinel Powders by Flame Spray Pyrolysis of a Magnesium Aluminum Double Alkoxide," J. Am. Ceram. Soc., 79, 1419-23, 1996.

[10] J.D. Kuntz, J.J. Roberts, M. Hough, N.J. Cherepy "Multiple Synthesis Routes to Transparent Ceramic Lutetium Aluminum Garnet," Scripta Mat., vol. 57, p. 960, 2007.

[11] F. Quarati, A.J.J. Bos, S. Brandenburg, C. Dathy, P. Dorenbos, S. Kraft, R.W. Ostendorf, V. Ouspenski, A. Owens, "X-ray and gamma-ray response of a 2" x 2" $\mathrm{LaBr}_{3}$ :Ce scintillation detector," Nucl. Instr. Meth. A, vol.574, 115-120, 2007.

[12] H. Campbell and B. K. Crone, "Efficient Plastic Scintillators Utilizing Phosphorescent Dopants" App. Phys. Lett. 90, 012117, 2007.

[13] J. Glodo, E. V. van Loef, N. J. Cherepy, S. A. Payne, and K. S. Shah, "Concentration Effects in Eu Doped $\mathrm{SrI}_{2}$, " Nuclear Science, IEEE Transactions on, vol. 57, pp. 1228-1232, 2010.
[14] K E Nelson, T B Gosnell, D A. Knapp, "The effect of gamma ray detector energy resolution on the ability to identify unknown radioactive sources," internal LLNL document, 2/25/2010.

[15] Payne, S.A.; Cherepy, N.J.; Hull, G.; Valentine, J.D.; Moses, W.W.; Choong, W.-S., "Nonproportionality of Scintillator Detectors: Theory and Experiment," IEEE Trans. Nucl. Sci., vol. 56, 2506 - 2512 (2009).

[16] P. Dorenbos. J.T.M. de Haas, and C.W.E. van Eijk, "NonProportionality in the Scintillation Response and the Energy Resolution Obtainable with Scintillation Crystals," IEEE Trans. Nucl. Sci., vol. 42, p. 2190, 1995. 